\title{
BMJ Staff's perception of abuse in Open healthcare: a Swedish qualitative study
}

\author{
Katarina Swahnberg, Barbro Wijma
}

To cite: Swahnberg K, Wijma B. Staff's perception of abuse in healthcare: $\mathrm{a}$ Swedish qualitative study. BMJ Open 2012;2:e001111. doi:10.1136/bmjopen-2012001111

- Prepublication history and additional material for this paper are available online. To view these files please visit the journal online (http://dx. doi.org/10.1136/bmjopen2012-001111).

Received 13 March 2012 Accepted 20 August 2012

This final article is available for use under the terms of the Creative Commons Attribution Non-Commercial 2.0 Licence; see http://bmjopen.bmj.com

For numbered affiliations see end of article

\section{Correspondence to} Dr Katarina Swahnberg; katarina.swahnberg@liu.se

\section{ABSTRACT}

Objective: The study aim was to apprehend staff's perception of abuse in healthcare (AHC) after an intervention based on 'Forum Play', and make comparisons to preintervention interviews and interviews with male and female patients. AHC can be described as a failing encounter from the patient's perspective.

Design: Qualitative interview follow-up study.

Setting: A Swedish Women's Clinic.

Participants: In a preintervention study 21 staff members were interviewed. Eligible for the follow-up study were 14 informants who had participated in the intervention. Four declined participation leaving ten informants for this study.

Intervention: During January 2008-January 2009, all staff members $(\mathrm{N}=136)$ were invited to participate in Forum Play workshops. Seventy-four participants took part in at least 1 of the 17 half-day workshops.

Primary outcome measures: Staffs perception of AHC.

Results: The core category, 'a summoning stone in the shoe', was constructed of five categories: 'Dehumanising the patient', 'Unacceptable: you are bound to act!', 'Ubiquitous', 'Unintentional' and 'Relative'. Forum Play had demonstrated possibilities to act even in seemingly 'impossible' situations, and that the taboo status of AHC was altered at the clinic. When our results were compared to those in the preintervention study, we found an increased awareness about AHC, more concrete examples of $\mathrm{AHC}$, a stronger empathy for patients, and fewer explanations, justifications and trivialisations of $\mathrm{AHC}$.

Conclusion: In this follow-up study staff's perception of AHC was closer to the patient's perspective. Compared to the preintervention interviews staff showed a greater willingness not only to acknowledge $\mathrm{AHC}$, but also to take on a responsibility to act in order to stop or prevent AHC. Explanations for this stance could be that Forum Play had showed staff that there were possibilities to act, and that the taboo status of AHC had been broken at the clinic.

\section{INTRODUCTION}

Negative encounters in healthcare has been described as medical errors, ${ }^{1}$ communication failures or medical mishaps, ${ }^{2}$ patient dissatisfaction, ${ }^{3}$ sexual misconduct, ${ }^{4}$ etc.

\section{ARTICLE SUMMARY}

Article focus

- The study objective was to apprehend changes in the attitude of healthcare staff to abuse in healthcare (AHC) after an intervention, based on 'Forum Play', developed by Augusto Boal.

- Our aim was to evaluate the intervention by means of a design allowing the findings from preintervention to be compared to those from postintervention qualitative interviews.

Key messages

- Informants' reported that Forum Play had demonstrated possibilities to act even in seemingly 'impossible' situations, that they had acted in such situations, and that the taboo status of AHC was broken at the clinic.

- When our results were compared to those in the preintervention study, we found an increased awareness about $\mathrm{AHC}$, more concrete examples of $\mathrm{AHC}$, a stronger empathy for patients, and fewer explanations, justifications and trivialisations of AHC.

- After an intervention with Forum Play workshops, staff showed a greater willingness not only to acknowledge $\mathrm{AHC}$, but also to take on the responsibility to act in order to stop or prevent AHC. The imperative to act against $\mathrm{AHC}$ in the present study stands out as the most important result of the intervention.

Strengths and limitations of this study

- To conduct qualitative interviews preintervention and postintervention gave us a deeper understanding of changes that might have been pointed out but not thoroughly explained by means of, for example, repeated quantitative measures.

- On the other hand, the approach also involves risks, for example, the authors' involvement in the project could be assumed to increase the risk for bias both on behalf of the researchers, that is, doing interpretations favourable to the project's success rate, as well as on behalf of the informants, that is, a social desirability bias.

Many of these negative encounters have to be investigated but what if there was no medical error or misconduct committed but the patient still felt abused? 
Abuse in healthcare (AHC) covers a phenomenon different from, for example, medical errors and patient satisfaction even if there might be overlapping cases. ${ }^{5}$

AHC has been investigated in the Nordic countries. It is a rather new concept that has been operationalised in The NorVold Abuse Questionnaire (NorAQ) (table 1). ${ }^{6-}$

${ }^{10}$ Based on NorAQ the prevalence in female gynaecology patients in the Nordic countries ranged between $13 \%$ and $28 \% .^{11}$ AHC is prevalent in Sweden; $14-20 \%$ in female and $8 \%$ in male clinical and population-based samples have had such experiences. ${ }^{8}$ 12-14

When we asked Swedish patients in qualitative interviews what AHC meant to them, both female and male patients expressed feelings of being disempowered and devalued. The core category in the female sample was a feeling of being 'nullified' and in the male sample 'mentally pinioned' ${ }^{15}{ }^{16}$ However, when staff was asked the same question (in the preintervention study), the answers were quite different. They explained theoretically what AHC could be, for example, transgression of ethical principles, but they were also occupied with explanations and justifications as to why AHC occurred, and the core category was 'ethical lapses'. In accordance with their ambiguity and inability to handle AHC, it was treated with silence and as a taboo. ${ }^{17}$ Moreover, staff's awareness of AHC was dependent on their possibilities to act; low awareness was seen when there were few possibilities to act. ${ }^{18}$

High prevalence of AHC, creating long-lasting suffering among patients and little awareness about the

\begin{tabular}{|c|c|}
\hline & AHC \\
\hline Mild abuse & $\begin{array}{l}\text { Have you ever felt offended or grossly } \\
\text { degraded while visiting health services, felt } \\
\text { that someone exercised blackmail against } \\
\text { you or did not show respect for your } \\
\text { opinion-in such a way that you were later } \\
\text { disturbed by or suffered from the } \\
\text { experience? }\end{array}$ \\
\hline $\begin{array}{l}\text { Moderate } \\
\text { abuse }\end{array}$ & $\begin{array}{l}\text { Have you ever experienced that a 'normal' } \\
\text { event while visiting health services, } \\
\text { suddenly became a really terrible and } \\
\text { insulting experience, without you fully } \\
\text { knowing how this could happen? }\end{array}$ \\
\hline $\begin{array}{l}\text { Severe } \\
\text { abuse }\end{array}$ & $\begin{array}{l}\text { Have you experienced anybody in health } \\
\text { service purposely-as you understood- } \\
\text { hurting you physically or mentally, grossly } \\
\text { violating you or using your body and your } \\
\text { subordinated position to your } \\
\text { disadvantage for his/her own purpose? } \\
\text { Answer alternatives (the same for all } \\
\text { questions) } \\
1=\text { no, } 2=y e s, \text { as a child ( }<18 \text { years), } \\
3=y e s, \text { as an adult ( } \geq 18 \text { years), } 4=y e s, \text { as } \\
\text { a child and as an adult }\end{array}$ \\
\hline
\end{tabular}

problem among staff forced us to design and test an intervention against AHC. The intervention was based on theories from ethics, sociology, cognitive theories and pedagogy. ${ }^{19-24}$

The interviews with staff mentioned above serves as a starting point in the present study that was conducted after workshops based on Forum play where the same group of staff could participate.

There is a long tradition of interventions that addresses the interpersonal component of quality of care. $^{25}$ Role play is one technique used for this purpose. ${ }^{26} 27$ What makes this study different is our focus on AHC. Augusto Boal, a Brazilian theatre director and pedagogue, developed many different theatre techniques to liberate people, and Theatre of the Oppressed (TO) is a characterising name used for all his techniques. Influenced by Paulo Freire's Pedagogy of the Oppressed, TO became a grassroots movement from the 1960s and on, offering techniques based on empowerment to equip people to transform the conditions in which they were living. ${ }^{19} 28$ Although TO is used worldwide to promote change evaluations of success rates are scarce. $^{29}$

The essence of Forum Play is to create a safe place in a group session, to make the moral conflict clear, to allow feelings but focus on action, and to practice new alternatives to act. Discovering and acting out many different solutions to a situation that at first seemed impossible to solve, instils hope in Forum Players. In this intervention, Forum Players are assumed to gradually feel brave enough to transfer their experiences into real life, and try out alternative ways at their work place to handle or prevent AHC.

For this study, we returned to the preintervention informants (staff) with the same research question, "What is AHC?" after an intervention against AHC based on Forum Play.

The study aim was to apprehend staff's perception of AHC after an intervention based on 'Forum Play', and make comparisons to preintervention interviews and interviews with male and female patients.

\section{METHODS}

\section{Procedure and material}

During the period January 2008-January 2009, all staff members at the study clinic, a women's clinic at a county hospital in the south of Sweden $(\mathrm{N}=136)$, were invited to participate in Forum Play workshops led by professional Forum Play leaders. ${ }^{30} 31$ All workshops were announced at the local hospital Intranet where staff could also register. Participation was voluntary and there was no limit to the number of workshops a staff member could participate in. Seventy-four participants took part in at least 1 of the 17 half-day workshops that were held (74/ $136=54 \%)$.

During the workshops, staff re-enacted (role-played) situations that they had experienced or heard of when 
patients had felt abused in healthcare. The situations were different from one workshop to another, but typically included a bystander who was not intervening but felt that he or she ought to do something. The bystander usually did not act because the situation seemed to be without possible 'solutions'. The scene was repeated until it was clear to everyone what the moral conflict was, and who was suffering the moral conflict. ${ }^{19}$ Then the scene was played again and the audience was encouraged to intervene. They could enter the scene and try to change the outcome by taking on the role of the person who suffered the moral conflict.

In a baseline study, we interviewed 21 staff members who were eligible for participating in the Forum Play intervention, and who represented four different staff categories. ${ }^{17} 18$ Eligible for the present study were those 14 informants from the original sample who had participated in the intervention (three staff members had left the clinic, and four had not participated in the intervention). Four declined participation (one gynaecologist and three auxiliaries). All interviews were booked by a coordinator employed at the clinic.

The two authors conducted ten individual semistructured interviews: two female and one male gynaecologist, one female administrator, four female midwives and two female auxiliaries. Individual interviews were preferred due to the sensitive nature of the topic that might evoke feelings of guilt and shame.

The analysis presented in this study is based on answers to open-ended questions similar to those in the preintervention study. The main question used for comparing results was: 'When I say abuse in healthcare, what is the first thing that comes to your mind?' Interviews lasted on average $60 \mathrm{~min}$. All interviews were tape-recorded and transcribed verbatim by a secretary.

Written informed consent was obtained from all participants before the interview. Our request to conduct the study had been approved by the regional ethical review board (Registration number 194-06).

\section{Analysis}

We choose a qualitative approach to collect and analyse data according to Barney Glaser but were also inspired by later work of Janice Morse and Kathy Chamaz. ${ }^{32-35}$ Constant comparative analysis was used to process data. ${ }^{33}$ The transcribed interviews were analysed line by line according to Glaser's scheme of open coding to generate substantive codes, that is, words or sentences with a relationship to the research question. ${ }^{32}{ }^{33}$ The substantive codes were constantly compared between interviews to generate new substantive codes and categories. Finally, the relationship between the categories was analysed and a core category that answered our research question was identified. ${ }^{32}$ No new substantive codes emerged after the fourth interview. All interviews were analysed to stabilise the categories and reach saturation. All categories are described in the result section and presented in table 2 .

\section{RESULTS}

The core category, 'a summoning stone in the shoe', was constructed of five categories: 'Dehumanising the patient', 'Unacceptable: you are bound to act!', 'Ubiquitous', 'Unintentional' and 'Relative'. Each category is described separately below. The interactions between the categories are described under the headline 'core category' at the end of the result section. Quotes are used to illustrate our findings.

\section{Dehumanising the patient}

This category was built on three substantive codes:

1. "Not finding out where the patient is"

According to the informants, AHC could signify several things:

Not to imagine what the patient is going through:

You have to imagine, and understand the things you say; what are the consequences... what do you do and what will be the consequences. How will it be in this situation? For sometimes an act can be rather innocent, and in some situations, [certain] behaviour can be completely catastrophic.

To belittle a patient's problem by comparing with other patient's problems:

Yes, to listen to what the other is talking about...to be focused on the one in front of you. Yes, seriously, even [when you] think that's a silly little thing compared to the death [a dying person] ...in the next room.

To be judgmental:

If someone is admitted, there are not so many of them here but, gipsies... Have you locked away your handbag? Where is my purse? They are judged awfully hard.

Lack of cultural awareness:

Table 2 Categories and core category answering the research question: what is abuse in healthcare (AHC)?

\begin{tabular}{|c|c|c|}
\hline $\begin{array}{l}\text { Categories in } \\
\mathrm{AHC}\end{array}$ & Function? & Core category \\
\hline Relative 7 & $\begin{array}{l}\text { Legitimising } \\
\text { AHC? }\end{array}$ & $\begin{array}{l}\mathrm{AHC} \text { is a } \\
\text { summoning stone }\end{array}$ \\
\hline Unintentional 8 & $\begin{array}{l}\text { Legitimising } \\
\text { AHC? }\end{array}$ & in the shoe! \\
\hline $\begin{array}{l}\text { Unacceptable: you } \\
\text { are bound to act! } 8\end{array}$ & $\begin{array}{l}\text { Protecting the } \\
\text { patient from } \\
\text { AHC? }\end{array}$ & \\
\hline Ubiquitous 9 & $\begin{array}{l}\text { Protecting the } \\
\text { patient from } \\
\text { AHC? }\end{array}$ & \\
\hline $\begin{array}{l}\text { Dehumanising the } \\
\text { patient } 10\end{array}$ & $\begin{array}{l}\text { Protecting the } \\
\text { patient from } \\
\text { AHC? }\end{array}$ & \\
\hline
\end{tabular}


Expecting that patients with a foreign background live by and accept Swedish norms like in the following example might also render in AHC, according to one informant who had had to console a crying patient after an examination.

When she came it was a shock for her [that it was a male gynaecologist] and she told them that...she was going to see a female [gynaecologist] and then they had answered her that well but you can't always get... what you ask for... if you seek help at such short notice then you have to take what you can get. Everything was supposed to be quick and she just felt that she was just...trouble for them... And she was...so sad afterwards.

2. "Saying things that are very abusive"

According to the informants, AHC can be something you say or the way you say it; a few words may turn a situation into a disaster for a patient.

One example: a patient with cancer was constantly throwing up. Staff had provided her with bags and bowls but nothing helped, repeatedly there was vomit everywhere: on the bedside table, in the bed and all over her things. Staff thought that she was capable of using the bags and bowls, and discussed between them if she did it on purpose. There were sighs among the staff, sometimes even audible to the patient, according to the informant. One day, a staff member asked the patient if she was going to continue like this when she would go home.

Another informant remembered her own first delivery: the baby's heart sounds were getting worse, the suction cup did not work, she had intravenous fluids running in both arms and she was screaming in pain. Then the doctor came up to her and said, 'Are we going to cooperate for hell's sake!' Afterwards she felt abused and despite her longing for another child it took years before she decided to have a second baby.

Informants said that they used to think that AHC had to be a major thing, but that they now realised that AHC was often an unexpectedly small thing, and that a good situation could turn into a disaster because of a small thing. As aforementioned, the sex of the examiner might sometimes be crucial for the patient for religious or other reasons, while some staff members may consider it a small thing.

3. "They must have felt very vulnerable"

An informant told us about a patient that she had known for a long time whom she thought of as extremely nervous and inadequate. The patient had told her that she was afraid of hospitals. Later she also told her that she had been forced to go through a gynaecological examination when she was a child, on suspicion that she had been sexually abused by or involved with an older boy.

... she [the mother] only said, "now we are going to town'. And then they brought her to the gynaecological ward and then they held her tightly and she was examined. And she screamed and she kicked and she was struggling with them. And she said that she can't forget this ...it is stuck with her that...that they pushed her down and forced her, and so on. So I think that's a typical example of abuse in the health care and for ten years I've been wondering what's wrong with this girl.

Power and power imbalance in relation to AHC was mentioned in several ways, for example, the exposed position a woman has during a gynaecological examination or the patients' dependency on staff's willingness to help and to be gentle to them: "You are not your own master then."

One informant was also pondering about her ability to really understand what it meant to be dependent and exposed as a patient:

...I still think that I can feel...that you can imagine...the dependency...get an understanding about how it is...I can never understand, but I can feel humble...I can share it...I can have respect and understand that she has something else with her that I haven't got.

AHC could also mean that advantage is taken of the power inherent of one's position, symbolised by, for example, the uniforms: “... when you put on your work clothes, then you have a kind of...how to say it, a power position."

\section{Unacceptable: you are bound to act!}

The informants were prone to positioning themselves against AHC by, for example, talking about how they had (re)acted against AHC, and that it could be done in a good way, "... but then I think you have an obligation... to rebuke. In a loving way." They also emphasised that the bystander had a very important role in noticing and stopping or preventing AHC, "because sometimes I think that it is the person who stands by...maybe more often senses when something goes wrong than the person who is [active] in the situation".

There were different strategies for intervening against potentially abusive situations.

One informant was concerned about open doors and meant that staff leaving doors open jeopardised a patient's integrity. She was struggling with this problem:

...it is an indication that you probably can't miss [with laughter in her voice]. No, but sometimes when you have been sitting in the auxiliaries' expedition, there is just a sliding door...there are patients sitting right outside and then I close the door...or when you... hear...that they... are in a room talking and so on. Close the doors... and I close that door [the sliding door] and then it's open again! And I close it.

Practical arrangements for preventing AHC were discussed:

...there are more discussions about this [now]. About... for example, open the door into a room where a patient 
is and...how to place patients in a room, and how many really have to come into a room. So, these kinds of questions.

It was also put forward that small talks over a cup of coffee could raise awareness about AHC among staff, but to talk to the patient, either before or after AHC had occurred, was seldom mentioned as an intervention. One informant interpreted this particular kind of silence as fear:

It must be some kind of ...fear to...realise that you are not perfect. Maybe! ... Of course if you ask then you have to be prepared...to do something about what the patient might bring up.

In other words, asking a patient about AHC might force staff to take action, for example, towards a colleague. Some informants stressed the importance of being earnest in such situations and talk directly to the staff involved as soon as possible. This was what the informant did who told us about the patient who expected to be examined by a female gynaecologist. When she had comforted the patient she asked her if she could talk to the staff member who had examined her, and if the patient wanted to participate in such a meeting. The patient declined

...I was allowed to tell...how she had experienced it...I was so disturbed by what she told me. So I felt that I had to find out if that was how it had happened. But he had not really experienced it that way...

Furthermore, there was a possibility to report upwards in the hierarchy: "I would not hesitate to...contact... [silence] a foreman, my bosses [if a patient was abused]." And there was a consensus on having an open climate at the clinic, and that it was important to be made aware when a patient was abused. Speaking up against AHC was considered an option for most informants:

That you say,' you can't behave like that'. So I believe that...people would tell you...I believe that there are few who would not dare to speak up...I believe they would speak to a colleague.

\section{Ubiquitous}

AHC was often described in a broad sense as something that can happen to anyone at any age: patients, staff, relatives and friends to the patient. Anybody can become a victim or an agent (actor or bystander) of AHC: “...we are abusing each other...all the way down to the patient..."

AHC was also interpreted as staff being abusive against other staff, for instance, by making remarks in a harsh way. It was also pointed out that a patient who had witnessed staff treating each other badly might feel hesitant to ask even important questions for their own sake.
One abusive situation between members of staff described as common was when a midwife called for a doctor and that doctor called for another doctor, and the two of them did not involve the midwife when they discussed the patient.

It was also hypothesised that staff experiencing abuse from other staff might subconsciously take it out on someone else: “...if I am abused then I will look for someone...that...I have power over.” And that someone is likely to be a patient: “...it is easier to abuse when there is some kind of power relation... and when there is a kind of malady between us."

However, patients abused by staff were considered the most serious kind of AHC: "...the most serious is if we, the staff...abuse patients or relatives. That is another situation I believe."

Informants also agreed that patients were the most common victims of $\mathrm{AHC}$, and that if patients abused staff it should be understood differently: "Because there might be...patients who abuse staff in many ways, so to say. But on the other hand, they are in another position...worry can turn you...rather nasty, really."

\section{Unintentional}

AHC was believed to be a common experience among patients. Most informants said that AHC was usually unintentional on behalf of the staff, and that often involved staff was not even aware that it had happened. "...they are not aware, surely. But then I have to... become aware of how people might experience what I do."

A variety of explanations of the occurrence of AHC were brought forward, and it was pointed out several times that AHC did not come from evilness in staff members, but rather from a lack of consideration and empathy.

Not being reflective could result in a routine manner or performance. One example given was that of an authority, like the gynaecologist who was often believed to be under time restraints, who simply follows an old habit: focusing on getting things done instead of on the patient. "...it's so easy to follow... the same footsteps all the time..."

Another example of unintentional AHC was when staff members made jokes among themselves about, for example, someone being fat, and other staff members were laughing without reflecting on what they were laughing at, or if they ought to put an end to it.

It was also brought forward that unawareness of AHC could be due to inadequate communication skills, for example, if staff was not sensible enough to read the patient's body language.

The uniqueness in each and everyone's characters was appreciated, but sometimes, if a colleague was known to be harsh without meaning it or even noticing it herself or himself, there was a moral conflict. A bystanding staff member would in such a situation understand that the patient might feel abused, and at the same time know 
that the 'harsh' staff member did not mean to abuse the patient. This was considered a difficult situation, but as one informant concluded

...it's about personality, too, so it's really difficult to know how to tackle it. It's interesting that people are different, but on the other hand you don't want those differences to befall the patients so that they feel abused, or maltreated.

\section{Relative}

The informants were provoked by the word 'abuse' in AHC, and prone to take a defending position against it. They thought of 'abuse' (kränkning in Swedish) as a very strong word, that was sometimes used too often and in an inappropriate way. The informants thought that, especially in the rest of the society (outside the hospital), the word 'abuse' had suffered inflation. "I think that 'abuse' may be a tough word...It's a worn out word or a word that is used incorrectly..."

Informants agreed that AHC was a difficult concept to define. On the one hand, AHC was considered a strong word, and yet AHC could be a small thing. "...there is no such...scientific quantitative concept [saying] that this is abuse."

The wording seemed important to the informants and a more neutral word for AHC was desired by some of the informants, for example (negative) encounters (bemötande in Swedish).

AHC was considered a personal experience, and it was expressed that patients were more or less vulnerable to this experience. It was also brought forward that there were reasonable experiences that made some patients more vulnerable to AHC than others, for example, through a history of abuse.

\section{Core category}

The three categories 'Dehumanising the patient', 'unacceptable: you are bound to act!' and 'ubiquitous' are strongly linked to each other in many ways, not the least because of their potentially patient protective components. The category 'Dehumanising the patient' implies not being seen as a human being, stripped of human value. The codes that filled out this category were characterised by moral imagination and respect for the patient's situation. The informants showed great insight into patients' vulnerability and their own responsibility in relation to AHC. The fact that the informants gave several detailed examples of AHC underlined their emotional engagement. This engagement was a strong reason for staff to adopt a clear position against AHC, expressed in the category 'unacceptable: you are bound to act!' It was also made clear that acting against AHC was beneficial not only for the patient but also for staff: "...that's what we really ought to do [talk to each other when we think a patient might feel abused] ...we take responsibility for each other that way."
The category 'ubiquitous', indicated that the informants were now more prone to recognise AHC. This openness could be seen as a mediator that enabled staff to talk about AHC, which probably contributed to a milieu where staff felt some pressure to also act against AHC. However, there were contradictions in the staff's definitions of AHC. To claim that AHC was 'unintentional' was a way to describe a fact, and at the same time make AHC trivial. Likewise, the discussion that rendered a 'relative' definition of AHC could be seen as a diversion from a topic that provoked awkward feelings. Both of these categories could be used to legitimise AHC.

\section{DISCUSSION}

This study focuses staff members' perception towards AHC after an intervention based on Forum Play.

\section{Comparing interviews from before and after the intervention}

In our preintervention studies, staff reported detached perceptions of AHC and AHC had a taboo status at the study clinic. ${ }^{17} 18$ They recognised AHC as 'transgressions of ethical principles' but stated that these actions were often justifiable from a staff perspective for various reasons. ${ }^{17}$ Staff's awareness of AHC also turned out to be a complex phenomenon restricted by their possibilities to act, for example, caused by hierarchies or because they did not know what to do since they had no tools or training in handling AHC. ${ }^{18}$ The strongest expressions of change in the present study, when compared to the preintervention studies, was the increased awareness about AHC, stronger empathy for patients displayed in more concrete examples of, and fewer explanations, justifications and trivialisations of AHC. The increase of concrete examples of AHC that staff had seen or heard of was most likely a manifestation of the increased awareness of AHC among staff. ${ }^{18}$

Moreover, the answers to the question, "What is AHC?" in the present study, are closer to the experiences of both female and male patients than those of the study that posed the same question to staff prior to the intervention, where the core category was 'ethical lapses'. ${ }^{15-17}$ Apparently, staff's perception of AHC were closer to the patient's perspective.

\section{The core category}

Despite the 'resistance' we found, the overall finding is that AHC summons responsibility and urges an itch to act among staff. From having been considered a matter of mishaps-'ethical lapses'-AHC had become 'a summoning stone in the shoe'. ${ }^{17}$ By this it is meant that acting against $\mathrm{AHC}$ had become imperative.

The imperative to act against AHC in the present study stands out as the most important finding. The possible mechanisms for this finding could be that, (1) Forum Play had showed staff that there were possibilities to act and (2) the taboo status of AHC had been 
broken at the clinic. The informants told us that AHC was present more often in their daily conversations, and it was even discussed during coffee breaks, that is, AHC had become a shared problem.

According to Galtung, direct events of violence are nurtured and legitimised by cultural and structural violence, forming a vicious triangle. ${ }^{20}{ }^{23}$ While events of direct violence often are visible, cultural and structural violence are often not. A taboo can exemplify cultural violence. Breaking the taboo could be seen as a way to delegitimise direct events of AHC, and Forum play may have been a useful tool for this purpose since the 'culture' had changed, and talking about and acting against AHC had become 'the right thing to do'. However, it cannot be ruled out that any intervention against AHC that merely drew attention to the topic would have been useful. Therefore it would be interesting to compare different strategies to counteract AHC in future studies.

\section{From disavowal to responsibility}

The resistance against and disavowal of AHC found in the preintervention studies had not only decreased, it had also changed character. ${ }^{17}{ }^{18}$ For example, before the intervention informants strongly emphasised that they were abused too. Now they had attained a more general and less defensive view; anybody could get involved in AHC as an actor or a victim. Moreover, it was considered much worse if a patient was abused by staff, because staff had more powerful positions than patients and they were entrusted with the patients' vulnerability.

AHC was still considered to be acted out unintentionally, but the argument was no longer used to explain or justify AHC. Instead it was used as an incentive to become more aware about AHC.

How to define AHC was still problematic to the informants. Obviously AHC had been a new terminology for them, but the wish to rename AHC into a more 'comfortable' concept is interesting. It is likely that the concept AHC gradually will be exchanged for the more neutral 'a failing encounter' at this clinic.

\section{Limitations}

One of the study limitations is that it is based on few interviews; only 10 of 21 informants took part in the follow-up study. In spite of this drawback we could establish that no new substantive codes emerged after the fourth interview. Early saturation indicates that there were more similarities than differences in staff's experiences of AHC. Six more interviews were conducted to fill up categories and assure saturation, but it cannot be ruled out that yet another interview could have added new information or that people who declined to participate in the follow-up interviews might have had very different views to those who did participate.

To conduct qualitative follow-up interviews gave us a deeper understanding of changes that might have been pointed out but not have been thoroughly explained by means of, for example, repeated quantitative measures. On the other hand, the approach also involves risks, for example, the authors' involvement in the project could be assumed to increase the risk for bias both on behalf of the researchers, that is, doing interpretations favourable to the project's success rate, as well as on behalf of the informants, that is, a social desirability bias. ${ }^{36}$ In an effort to counteract these biases, external independent researchers repeated interviews as well as analyses. An external researcher analysed de novo the interviews in the present study. This analysis also showed that staff's perception of AHC had approached the patient perspective. ${ }^{37}$ New interviews were conducted by a consultant who was not involved in the project and with a different sample of staff who had also participated in the intervention. The results described a positive change from before till after the intervention, not only in perception but also in actions. Several examples were given where staff members had been 'experimenting' with different ways to prevent or handle AHC, also where it meant confronting a colleague. ${ }^{38}$

\section{CONCLUSION}

In this follow-up study staff's perception of AHC were closer to the patient's perspective. Compared to the preintervention interviews staff showed a greater willingness not only to acknowledge AHC, but also to take on a responsibility to act in order to stop or prevent AHC. Explanations for this stance could be that Forum Play had showed staff that there were possibilities to act, and that the taboo status of AHC had been broken at the clinic.

Author affiliations

Division of Gender and Medicine, Department of Clinical and Experimental Medicine, Linköping University, Linköping, Sweden

Contributors Both authors developed the idea for the study, participated in its design, and conducted the interviews. KS did the qualitative analysis and both authors participated in drafting and revision of the manuscript.

Funding The Swedish Research Council.

Competing interests None.

Ethics approval The regional ethical review board in Linköping, Sweden (Registration number 194-06).

Provenance and peer review Not commissioned; externally peer reviewed.

Data sharing statement No additional unpublished data are available from this study.

\section{REFERENCES}

1. McFadden KL, Stock GN, Gowen CR III,. Exploring strategies for reducing hospital errors. J Health Manage 2006;51:123-35 discussion 36

2. Sutcliffe KM, Lewton E, Rosenthal MM. Communication failures: an insidious contributor to medical mishaps. Acad Med 2004;79:186-94.

3. Coyle J, Williams B. Seeing the wood for the trees: defining the forgotten concept of patient dissatisfaction in the light of patient satisfaction research. Int J Health Care Qual Assur Inc Leadersh Health Serv 1999;12:i-ix.

4. Lamont JA, Woodward C. Patient-physician sexual involvement: a Canadian survey of obstetrician-gynecologists. Can Med Assoc J 1994;150:1433-9. 
5. Bruggemann AJ, Wijma B, Swahnberg K. Abuse in health care: a concept analysis. Scand J Caring Sci 2012;26:123-32.

6. Wijma B, Schei B, Swahnberg K, et al. The NorVold Abuse Questionnaire. Linköping: Division of Gender and Medicine, Faculty of Health Sciences, Linköping University, 2004.

7. Wijma B, Schei B, Swahnberg K, et al. Emotional, physical, and sexual abuse in patients visiting gynaecology clinics: a Nordic cross-sectional study. Lancet 2003;361:2107-13.

8. Swahnberg K. Prevalence of gender violence. Studies of four kinds of abuse in five Nordic countries [Doctoral Thesis]. Faculty of Health Sciences, Linköping, Sweden, Linköping University, 2003.

9. Swahnberg K. NorVold Abuse Questionnaire for men (m-NorAQ): validation of new measures of emotional, physical, and sexual abuse and abuse in health care in male patients. Gend Med 2011;8:69-79.

10. Swahnberg K, Wijma B. The NorVold Abuse Questionnaire (NorAQ) validation of new measures of emotional, physical, and sexual abuse, and abuse in the health care system among women. Eur $J$ Public Health 2003;13:361-6.

11. Swahnberg K, Schei B, Hilden M, et al. Patients' experiences of abuse in health care: a Nordic study on prevalence and associated factors in gynecological patients. Acta Obstet Gynecol Scand 2007:86:349-56.

12. Swahnberg K, Davidsson J, Hearn J, et al. Men's experiences of emotional, physical and sexual abuse, and abuse in health care: a cross-sectional study of a Swedish random male population sample. Scand J Public Health 2011;40:191-202.

13. Swahnberg K, Hearn J, Wijma B. Prevalence of perceived experiences of emotional, physical, sexual, and health care abuse in a Swedish male patient sample. Violence Vict 2009;24:275-86.

14. Swahnberg K, Wijma B, Schei B, et al. Are sociodemographic and regional and sample factors associated with prevalence of abuse? Acta Obstet Gynecol Scand 2004:83:276-88.

15. Swahnberg K, Thapar-Bjorkert S, Bertero C. Nullified: women's perceptions of being abused in health care. J Psychosom Obstet Gynaecol 2007;28:161-7.

16. Swahnberg K, Wijma B, Hearn J, et al. Mentally pinioned: men's perceptions of being abused in health care. Int $J$ Mens Health 2009;8:60-71.

17. Swahnberg K, Zbikowski A, Wijma B. Ethical lapses: staff's perception of abuse in health care. J Psychosom Obstet Gynaecol 2010;31:123-9.

18. Swahnberg K, Wijma B. Staff's awareness of abuse in health care varies according to context and possibilities to act. J Psychosom Obstet Gynaecol 2011;32:65-71.

19. Boal A. Games for actors and non-actors. London/NewYork: Routledge, 1992.
20. Galtung J. Violence, peace and peace research. J Peace Res 1969;6:167-91.

21. Glover J. Humanity. A moral history of the twentieth century. London: Pimlico, 2001.

22. Zimbardo P. The Lucifer effect. Understanding how good people turn evil. New York: Random House, Inc, 2008.

23. Galtung J. Cultural violence. J Peace Res 1990;27:291-305.

24. Beck J. Cognitive therapy: basics and beyond. New York: The Guilford Press, 1995.

25. Fonn S, Mtonga AS, Nkoloma HC, et al. Health providers' opinions on provider-client relations: results of a multi-country study to test health workers for change. Health Policy Plan 2001;16(Suppl 1):19-23.

26. Fonn S, Xaba M. Health workers for change: developing the initiative. Health Policy Plan 2001;16(Suppl 1):13-18.

27. Ammentorp J, Kofoed P-E. Being a patient in your own department. Patient Educ Couns 2010;81:142-3.

28. Freire P. Pedagogy of the oppressed-divide and oppress. Casa De Las Americas 1986;(159):148-51.

29. Österlind E. Acting out of habits - can theatre of the oppressed promote change? Boal's theatre methods in relation to Bourdieu's concept of habitus. Res Drama Educ J Appl Theatre Perform 2008;13:71-82.

30. Stocker SS. Staging the moral imagination in the health care setting. Linköping: Division of Gender and Medicine, Faculty of Health Sciences, Linköping University, 2011.

31. Josephson A. Praktisk kunskap i att förhindra kränkningar. Rapport om dramapedagogiskt arbete med vårdpersonal (Practical knowledge in counteracting abuse in health care. Report on drama pedagogic work among health care staff). Linköping: Division of Gender and Medicine, Faculty of Health Sciences, Linköping University, 2011.

32. Glaser B. Theoretical sensitivity. 4th edn. Mill Valley, CA: Sociology Press, 1978

33. Glaser B. Basics of grounded theory analysis. Emergence versus forcing. Mill Valley, CA: Sociology Press, 1992.

34. Morse JM. Developing grounded theory. The second generaton. Walnut Creek: Left Coast Press, INC, 2009.

35. Charmaz K. Constructing grounded theory. A practical guide through qualitative analysis. London: Sage Publications Ltd, 2009.

36. Saunders DG. Procedures for adjusting self-reports of violence for social desirability bias. J Interpers Violence 1991;6:336-44.

37. Swahnberg K, Berterö C. Minimizing human dignity: staff's perception of abuse in health care, 2012.

38. Nilsson A. Evaluering av projektet "kränkningar i vården" (Evaluation of the project "abuse in health care"). In: Swahnberg K. Linköping: Division of Gender and Medicine, Faculty of Health Sciences, Linköping University, 2010. 